\title{
Awareness of Physicians Working in Kayseri of the Age Limits Related to the Use of Cough and Cold Medicines in Children
}

\author{
Cem Turanoğlu 1, Ayşenur Paç Kısaarslan², Yasemin Altuner Torun ${ }^{3}$, Bahadır İnan ${ }^{1}$ \\ ${ }^{1}$ Department of Pediatrics, Kayseri Training and Research Hospital, Kayseri, Turkey \\ ${ }^{2}$ Department of Pediatric Rheumatology, Kayseri Training and Research Hospital, Kayseri, Turkey \\ ${ }^{3}$ Department of Pediatric Hematology, Kayseri Training and Research Hospital, Kayseri, Turkey
}

\begin{abstract}
Introduction: The purpose of this study is to examine the awareness of physicians concerning the age limit regulations related to the use of cough and cold medicines (CCM) in children.

Methods: A questionnaire including 12 questions was distributed to 180 pediatricians in Kayseri. In the first part of the questionnaire, the questions were covering demographic characteristics. In the second part, physicians were asked about the drugs they were prescribing and that were among 30 drugs for which the age limits were changed.

Results: Of the180 practitioners who participated in the study, 91 (50.56\%) were aware of a new regulation on the age limits and CCM use. However, only 5 physicians involved in the study (2.77\%) preferred the new arrangement where the appropriate age for all the drugs was determined.

Discussion and Conclusion: Physicians' awareness about the new regulations regarding the age limits and CCM use was at a low level. Integrating up-to-date drug guidelines into hospital and family medicine information management systems will contribute significantly to the elimination of such shortcomings.

Keywords: Awareness; common cold; medicine; physician.
\end{abstract}

C ommon cold is an acute viral infection of the upper respiratory tract with prominent symptoms of nasal discharge and obstruction. Young children are exposed to common cold 6-8 times a year on average. However, $10 \%-$ $15 \%$ of these children contract this disease 12 times a year [1]. In the symptomatic treatment of common cold, antihistamines, antitussives, decongestants, and expectorants are used intensively [2].

The use of over-the-counter cough and cold medicines (CCM) has become controversial ${ }^{[3,4]}$, Indeed, studies have demonstrated that although CCM are effective in adults, benefits of such drugs cannot be proven in children, and they have serious adverse effects. In the United States, 20 deaths related to the use of CCM between 2000 and 2007 were reported ${ }^{[4]}$. Drugs containing more than one of the active ingredients such as phenylephrine, dextromethorphan, pseudoephedrine, guaiphenesin, and diphenhydramine agents have been held responsible for most of these cases.

Regulations with regard to the age limits of CCM use in our country have been implemented by the Ministry of Health $(\mathrm{MoH})$ in 2008,2011 , and $2013^{[5-7]}$. The purpose of this study is to determine physicians' awareness of the regulations regarding the age limitations of their use in children.

Correspondence (iletişim): Cem Turanoğlu, M.D. Kayseri Egitim ve Arastirma Hastanesi Cocuk Sagligi ve Hastaliklari Klinigi, Kayseri, Turkey Phone (Telefon): +90 5336355484 E-mail (E-posta): drturanoglu@hotmail.com

Submitted Date (Başvuru Tarihi): 30.01.2018 Accepted Date (Kabul Tarihi): 14.04.2018

Copyright 2018 Haydarpaşa Numune Medical Journal

This is an open access article under the CC BY-NC license (http://creativecommons.org/licenses/by-nc/4.0/). 


\section{Materials and Methods}

This study was carried out between July 1, 2017, and October 30, 2017, and it included 220 physicians (pediatricians, general practitioners, and family medicine specialists), who actively provided services for the pediatric age group in the province of Kayseri. An approval of the Kayseri Training and Research Hospital Clinical Research Ethics Board was obtained for this study (2017/315). A questionnaire consisting of 12 questions was distributed to the physicians who submitted their consent forms. The data in the questionnaire forms were collected for the study. Physicians and assistants who did not provide active outpatient services were excluded from the study.

In the first part of the questionnaire, in addition to demographic characteristics of the participants, questions were asked about whether the physicians knew about the amendments in regulations implemented by the $\mathrm{MoH}$ concerning the age limitations in CCM use in children, and if they had been informed, they were asked from where, and for which active ingredients they got this information. In the second part, they were asked about from what age they preferred to prescribe, and which CCMs among 30 drugs in the market containing active ingredients singly or in combination. To facilitate their recall, commercial drug names containing these active ingredients were listed. According to the Anatomical Therapeutic Chemical Classification (ATC) code, CCMs for which the participants were asked questions about the age limitations in their use were divided into four groups (Table 1).

\section{Statistical Analysis}

The SPSS version 24 program was used to evaluate data obtained in the study. The distribution of responses given to the questions with more than one alternative (questions for which the participant could select more than one option) was determined by the ticked options. The consistency coefficient (Cronbach's alpha) was tested to test the reliability of the questionnaire used. A chi-square test was used to evaluate the intergroup discontinuous data. Continuous data that did not fit a normal distribution pattern were assessed by the Kruskal-Wallis $\mathrm{H}$ test. A p value $<0.05$ was considered statistically significant.

\section{Results}

Initially, 220 physicians were included in the study. Due to various reasons (physicians who did not fill out the forms completely or who did not want to participate, participants who did not deliver the forms, etc.), we ended up with 180
Table 1. List of drugs containing active ingredients, singly or in combination, for which the info on the age of application was changed by the Ministry of Health

1. Cold Medicines (ATC Code R05X)

*triprolidine+pseudoephedrine+dextromethorphan

* paracetamol+chlorpheniramine

*paracetamol+chlorpheniramine+pseudoephedrine

* paracetamol+chlorpheniramine maleate+oxolamine citrate

*dextromethorphan+pseudoephedrine+chlorpheniramine

maleate

*terbutaline+guaiphenesin

*ephedrine+guaiphenesin

*ibuprofen+chlorpheniramine maleate+pseudoephedrine

*paracetamol+chlorpheniramine maleate+phenylephrine

*pseudoephedrine+guaiphenesin

* diphenhydramine+ammonium chloride+sodium citrate

+menthol

*dextromethorphan+guaiphenesin+pseudoephedrine

*ibuprofen+chlorpheniramine

* paracetamol+chlorpheniramine+pseudoephedrine

*paracetamol+guaiphenesin+pyrilamine maleate

+chlorpheniramine

* phenylephrine+guaiphenesin+diphenhydramine

*pseudoephedrine+chlorpheniramine+dextromethorphan

+paracetamol

*pseudoephedrine+dextromethorphan+paracetamol

+ doxylamine succinate

2. Cough-Suppressant Drugs (ATC Code R05DB27)

*levodropropizine

*levodropropizine (drops)

*levodropropizine+chlorpheniramine

*oxolamine phosphate

*butamirate citrate

3. Systemic Nasal Decongestants (ATC Code R01BA52)

*triprolidine $\mathrm{Hcl}+$ pseudoephedrine

*pseudoephedrine

4. Topical Nasal Decongestants (ATC Code R01AA05)

*oxymetazoline $0.01 \%$

*oxymetazoline $0.025 \%$

*oxymetazoline $0.05 \%$

${ }^{*}$ xylometazoline $0.05 \%$

${ }^{*}$ xylometazoline $0.1 \%$

ATC: Anatomical therapeutic chemical classification.

physicians. To test the reliability of the questionnaire applied to participants, the Cronbach's alpha coefficient was checked, and the Cronbach's alpha value was found to be 0.931 (>0.7). The demographic characteristics of the physicians involved in the study are shown in Table 2.

The first five questions asked the information about the 
Table 2. Demographic characteristics of physicians participating in the study

$\begin{array}{lc}\text { 1. Distribution of physicians according to their specialties } \\ \text { Specialty } & \mathbf{n}(\%) \\ \text { General practitioner } & 123(68.3) \\ \text { Family medicine specialist } & 12(6.7) \\ \text { Pediatrician } & 45(25) \\ \text { Total } & 180(100) \\ \text { 2. Age range } & \\ \text { Age range (years) } & \mathbf{n}(\%) \\ 24-35 & 55(30.6) \\ 36-45 & 65(36.1) \\ 46-55 & 46(25.6) \\ >55 & 14(7.7) \\ \text { Total } & 180(100)\end{array}$

3. For how long have the physicians worked in their field of medicine?

\begin{tabular}{lc} 
Duration (years) & $\mathbf{n}(\%)$ \\
$0-5$ & $43(23.9)$ \\
$6-10$ & $28(15.5)$ \\
$11-15$ & $39(21.7)$ \\
$>16$ & $70(38.9)$ \\
Total & $180(100)$ \\
\hline
\end{tabular}

CCMs prescribed by the physicians taking part in the study. The physicians' responses are shown in Table 3.

Ninety-one physicians who knew about the amendments in the relevant regulations concerning the age limits in the use of CCMs were asked about their knowledge about ingredients, and they indicated that they most frequently got the information about pseudophedrine, chlorpheniramine, and ephedrine (Table 4).

When the answer to the question "I do not prescribe" was accepted correctly among the 30 drugs for which the age limits were examined, only 5 physicians $(2.77 \%)$ out of the 180 participants preferred to prescribe the drug fully in compliance with the new amendment in the regulation. On the other hand, it was found that drugs listed in the 1-5 $(n=70 ; 38.8 \%) ; 6-10(n=56 ; 31.1 \%) ; 11-15 \quad(n=25 ; 13.8 \%)$; $16-20(n=19 ; 10.5 \%)$; and $\geq 21(n=5 ; 2.7 \%)$ rows of the questionnaire were not prescribed by the respective number of physicians. It was found that pediatricians prescribed $85 \%$, general practitioners $71.81 \%$, and family medicine specialists $66.68 \%$ of the drugs in compliance with the new amendment in the regulation. The prescribing rates of common cold medicines, cough suppressants, and systemic and nasal decongestants by pediatricians in compliance with the new amendment in the regulation concerning CCMs were statistically significantly higher relative to
Table 3. Responses of the physicians to the questions about prescribed cough and common cold medicines (CCM)

$\begin{array}{lc}\text { 1. Types of the sources of information about prescribed CCM } \\ \text { Sources of Information } & \mathbf{n}(\%) \\ \text { Drug guides } & 61(20.7) \\ \text { Internet } & 115(39.1) \\ \text { Short product information } & 61(20.7) \\ \text { Representative of the pharmaceutical firm } & 30(10.2) \\ \text { I don't have the need to be informed } & 27(9.3) \\ \text { Total } & 294(100)\end{array}$

2. The number (\%) of physicians who faced parental objection or opposition with regard to the age limitations of the prescribed CCM

$\begin{array}{lc} & \mathbf{n}(\%) \\ \text { Yes } & 62(34.4) \\ \text { No } & 118(65.6) \\ \text { Total } & 180(100)\end{array}$

3. The number (\%) of physicians who had information available about the age limitations with regard to CCM application

$\begin{array}{lc} & \mathbf{n}(\%) \\ \text { Yes } & 91(50.6) \\ \text { No } & 89(49.4) \\ \text { Total } & 180(100)\end{array}$

4. Sources of information on age limitations with regard to CCM

Sources of Information $\quad$ n (\%)

Pharmaceutical firms $\quad 45(34.1)$

Others $33(25)$

Instructions for use 32 (24.2)

The institute where the physician was employed $\quad 17$ (12.9)

Letters from the Ministry of Health addressed 5 (3.8)

to physicians

Total

$132(100)$

Table 4. Active ingredients that information was obtained for their age limits of use by indicated number (\%) of physicians

\begin{tabular}{lc}
\hline Active ingredient & $\mathbf{n}(\%)$ \\
\hline Pseudoephedrine & $74(55.6)$ \\
Chlorpheniramine & $20(15)$ \\
Phenylephrine & $8(6)$ \\
Ephedrine & $7(5.3)$ \\
Butamirate & $3(2.3)$ \\
Guaifenesin & $3(2.3)$ \\
Pheniramine maleate & $3(2.3)$ \\
Dextromethorphan & $2(1.5)$ \\
Oxolamine & $1(0.8)$ \\
Others & $12(9.1)$ \\
Total & $133(100)$ \\
\hline
\end{tabular}


general practitioners and family physicians. However, the difference was not statistically significant for topical nasal decongestants (Table 5).

The rates of physicians' non-preference among 30 medicines investigated in the survey differed among family physicians (12.25\%), general practitioners (13.6\%), and pediatricians $(20.17 \%)$. The rate of non-prescribing, excluding topical nasal decongestants, by pediatricians was statistically significantly higher when compared with family physicians and general practitioners (Table 6).

Seventy-four participants who stated that they were informed about the age limitations of pseudoephedrine application were further evaluated for 11 drugs that included this ingredient. Although they got information about these drugs, it was revealed that an average of $34 \%$ of these 11 drugs was still prescribed in accordance with the previously determined age limit.

\section{Discussion}

All of the physicians involved in this study had a lower level of awareness of the new regulations regarding the age limitations of CCM application.

However, the awareness of pediatricians was relatively higher when physicians participating in the study were divided into groups.

In 2007, the US Food and Drug Administration took an action to limit the use of CCMs sold as over-the-counter for small children ${ }^{[8]}$. On top of this, drug manufacturers in the United States voluntarily withdrew their medications from the marketplace in 2007 to make a label change stating that the drug should not be applied under 2 years of age [9]. In 2008, a changed product label of these drugs prohibited the use of CCMs under the age of 4 years ${ }^{[10]}$. In this process, the American Academy of Pediatrics, went even further, suggesting that these drugs should not be used under the age of $6^{[11]}$. The Canadian $\mathrm{MoH}$ also reported in 2009 that they decided to ban the use of these drugs in children under 6 years of age because of the following four reasons. First, the weight of some children between the ages of 2 and 6 can be as low as those under 2 years of age. Second, Canadian and foreign experts have reported the harmful effects of these medicines. Third, children under 6 years of age are more likely to have a cold and therefore more likely to be exposed to these medications. Fourth, children under 6 years of age are less able to communicate with their parents about the medication side effects ${ }^{[12]}$.

The initiation of label changes in CCMs has resulted in fewer adverse events associated with these drugs in the United States and side effects associated with the use of these drugs in emergency departments ${ }^{[13-17]}$. There are studies in the literature about health professionals' attitudes toward CCMs. Mazer-Amirshahi et al. ${ }^{[18]}$ conducted a study comparing the attitudes of health personnel using CCMs between 2005 and 2006 and between 2009 and 2010. These limitations and recommendations showed that the rates of drug use did not change in children under 2 years of age in emergency services and out patient clinics.

However, the number of common cold prescriptions written for patients after their discharge was significantly re-

Table 5. Prescription rates of cold and cough medicines according to medical specialties

\begin{tabular}{|c|c|c|c|c|}
\hline Drugs & $\begin{array}{c}\text { General } \\
\text { Practitioner, \%, } n=123\end{array}$ & $\begin{array}{c}\text { Family Medicine } \\
\text { Specialist, \%, n=12 }\end{array}$ & $\begin{array}{c}\text { Pediatricians, } \\
\%, n=45\end{array}$ & $\mathbf{p}$ \\
\hline Cold medicines (18) & $69.3(1536)^{\mathrm{a}}$ & $61.5(133)^{a}$ & $82.3(667)^{b}$ & 0.000 \\
\hline Systemic nasal decongestants (2) & $64.6(159)^{\mathrm{a}}$ & $54.1(13)^{\mathrm{a}}$ & $81.1(73)^{b}$ & 0.022 \\
\hline Topical nasal decongestants (5) & $76.4(470)^{a}$ & $71.6(43)^{\mathrm{a}}$ & $71.6(190)^{\mathrm{a}}$ & 0.313 \\
\hline
\end{tabular}

A statistically significant difference exists between the groups labeled with superscript ${ }^{\mathrm{a}}$ and ${ }^{\mathrm{b}}$.

Table 6. Non-preference rates of cold and cough medicines according to medical specialties

\begin{tabular}{|c|c|c|c|c|}
\hline Drugs & $\begin{array}{c}\text { General } \\
\text { Practitioner, \%, n=123 }\end{array}$ & $\begin{array}{c}\text { Family Medicine } \\
\text { Specialist, \%, n=12 }\end{array}$ & $\begin{array}{c}\text { Pediatricians, } \\
\%, n=45\end{array}$ & $\mathbf{p}$ \\
\hline Cold medicines (18) & $46.2(1025)^{a}$ & $44.4(96)^{a}$ & $65.4(530)^{b}$ & 0.000 \\
\hline Systemic nasal decongestants (2) & $40.2(99)^{\mathrm{a}}$ & $41.6(10)^{\mathrm{a}}$ & $75.5(68)^{\mathrm{b}}$ & 0.000 \\
\hline Topical nasal decongestants (5) & $30.8(190)^{\mathrm{a}}$ & $20.0(12)^{a}$ & $35.8(95)^{\mathrm{a}}$ & 0.207 \\
\hline
\end{tabular}

A statistically significant difference exists between the groups labeled with superscript ${ }^{a}$ and ${ }^{b}$. 
duced in both groups. In a study by Şen et al. ${ }^{[19]}$ realized in Italy and in the Netherlands in 2010, the prescribing rates of CCMs were examined in children under 2 years after the announcement of national and international warnings. In Italy, a slight decrease in the prescribing rates of all CCMs was detected; however, an increase in the prescribing rates of these drugs was noted in the Netherlands. As a result, it has been stated that drug companies should clearly indicate that the use of these medicines in small children is dangerous to raise awareness among health care professionals.

In parallel with the discussions in the world, in Turkey, the General Directorate of Pharmaceuticals and Pharmacy sent a letter to pharmaceutical companies and the unions dated March 31, 2008, concerning an arrangement related to the prescription of $\mathrm{CCMs}^{[5]}$. In this letter, there was an addition to the statement in the warnings/precautions section of the instructions of the short product information for drugs containing brompheniramine, chlorpheniramine and diphenhydramine, dextromethorphan, pholcodine, guaiphenesin, ipecacuanha, phenylephrine, pseudoephedrine, ephedrine, oxymetazoline that prohibited the use of these drugs in children without absolute and compulsory indications.

After a while, on November 18, 2011, the General Directorate of Pharmaceuticals and Pharmacy declared that "based on the decisions made by the Advisory Commission on Pharmacology of the Ministry of Health and the Advisory Commission on Licensing Regulation on Human Medicinal Products for Human Use in consideration of its possible risks and adverse effects, for pharmaceutical preparations containing pseudoephedrine singly or in combination the following statements should be added, and required changes should be made in the relevant sections of the SPC/SPO" ${ }^{[6]}$.

Accordingly, they proposed four basic recommendations. Proprietary drugs in liquid forms that contain a combination with an antipyretic agent (such as paracetamol, ibuprofen) must not be used in patients aged younger than 6 years, and the formulations in liquid forms combined with other agents must not be used in children younger than 12 years of age. Liquid preparations containing only pseudoephedrine alone should not be used in patients younger than 6 years of age. Preparations in solid forms containing pseudoephedrine singly or in combination should not be used in children younger than 12 years.

Turkey's Pharmaceuticals and Medical Devices Agency issued an update on July 23, 2013, regarding CCMs currently in use ${ }^{[7]}$. The age limits for the use of the prepa- rations containing a single active ingredient including levodropropizine, guaiphenesin, brompheniramine, chlorpheniramine, phenylephrine, xylometazine, diphenhydramine, butamirate citrate, dextromethorphan, oxymetazoline, pentoxyverine, oxolamine, noscapine, and cloperastine were increased.

In our study, only $2.77 \%$ of the participants prescribed CCMs in compliance with new arrangements in regulations, while $49.4 \%$ of the respondents were not aware of the changes, indicating that physicians' awareness of this issue was not at a satisfactory level. In addition, $50.6 \%$ of the physicians who were informed about the changes were knowledgeable about the age limits related to very few active ingredients. Physicians who received information about pseudoephedrine were evaluated separately, and it was also found that approximately $34 \%$ of them preferred to prescribe these drugs considering previous age limits. This situation suggests that physicians do not benefit from current sources.

Physicians prescribing these drugs without definitely established absolute indications for patients beyond the defined age limits can present serious problems in terms of patient health and may expose physicians to serious legal troubles. Some (34.4\%) proportion of the physicians face the parental objection about the age limits of prescription drugs, which can be evaluated as steps toward possible legal problems.

The strength of our study, as far as we know, is that it reveals the first batch of data in our country on his issue, to the best of our knowledge. The limitations of the study are the low number of physicians in the family physician group (the number in the province is low) and its local frame.

As a result, integrating both the hospital and family medicine information management systems into the current drug guidelines will make a significant contribution to the elimination of such malpractices. Where integration is not possible, physicians should reexamine their current sources of CCMs. In addition, sending letters by $\mathrm{MoH}$ to relevant physicians may be a significant contribution to the elimination of this problem.

Ethics Committee Approval: An approval of the Erciyes University Clinical Research Ethics Board was obtained for this study (2017/315).

Peer-review: Externally peer-reviewed.

Conflict of Interest: None declared.

Financial Disclosure: The authors declared that this study received no financial support. 
Authorship Contributions: Concept: C.T., A.P.K., Y.A.T.; Design: C.T., A.P.K.; Data Collection or Processing: C.T., B.I; Analysis or Interpretation: C.T., A.P.K.; Literature Search: C.T., B.I.; Writing: C.T., A.P.K.

\section{References}

1. Miller EK, Williams JH. The Common Cold. In: Kliegman RM, Stanton BF, St Geme JW, Schor NF. Nelson Texbook of Pediatrics. 20th ed. Philadelphia; 2016. p. 2011-4.

2. Vernacchio L, Kelly JP, Kaufman DW, Mitchell AA. Medication use among children $<12$ years of age in the United States: results from the Slone Survey. Pediatrics 2009;124:446-54. [CrossRef]

3. Schroeder K, Fahey T. Over-the-counter medications for acute cough in children and adults in ambulatory settings. Cochrane Database Syst Rev 2004:CD001831. [CrossRef]

4. Dolansky G, Rieder M. What is the evidence for the safety and efficacy of over-the-counter cough and cold preparations for children younger than six years of age? Paediatr Child Health 2008;13:125-7. [CrossRef]

5. T.C.SağlıkBakanlığı İlaç ve Eczacılık Genel Müdürlüğü. Sendika, Dernek ve Firma Duyuruları, Soğuk algınlığı ve öksürük ilaçları. Available at: https://www.titck.gov.tr/PortalAdmin/Uploads/ Titck/Dynamic/\%C4\%B0la\%C3\%A7\%20G\%C3\%BCvenli\%C4\% 9Fi\%20\%C4\%B 0zleme,\%20De\%C4\%9Ferlendirme $\% 20 \%$ C5\% 9 Eube $\% 20 \mathrm{M} \% \mathrm{C} 3 \% \mathrm{BCd} \% \mathrm{C} 3 \% \mathrm{BCr}-$ I\%C3\%BC\%C4\% 9F\%C3\%BC\%20-\%20T\%C3\%9CFAM/ Soguk_alginligi_14f9cb4.pdf. Accessed Aug 1, 2018.

6. T.C. Sağlık Bakanlığı İlaç ve Eczacılık Genel Müdürlüğü. Sendika, Dernek ve Firma Duyuruları, Pseudoefedrin içeren müstahzarlar. Available at: https://www.titck.gov.tr/PortalAdmin/Uploads/Titck/Dynamic/Ruhsatl\%C4\%B1\%20 \% C $3 \%$ 9 Cr \% C $3 \%$ B C n le r - 2\% $20 \%$ C $5 \% 9$ E u be \% 20 M\%C3\%BCd\%C3\%BCrl\%C3\%BC\%C4\%9F\%C3\%BC/1699_ aa5d8ea.pdf. Accessed Aug 1, 2018.

7. T.C. Sağlık Bakanlığı, Türkiye İlaç ve Tıbbi Cihaz Kurumu; Sendika, Dernek ve Firma Duyuruları, 23.07.2013. Available at: https://titck.gov.tr/storage/dynamicModulesAttachment/0484_587b162.pdf. Accessed Jan 02, 2019.

8. US Food and Drug Administration. Briefing information: joint meeting of the Nonprescription Drugs Advisory Committee and the Pediatric Advisory Committee, October 18-19, 2007. Available at: http://www.fda.gov/ ohrms/dockets/ac/07/briefing/2007-4323b1-00-index.htm. Accessed Oct 31, 2013.

9. Consumer Healthcare Products Association. Makers of OTC cough and cold medicines announce voluntary withdrawal of oral infant medicines. Available at: http://www.chpa-info. org/10_11_07_OrallnfantMedicines.aspx. Accessed Jun 7, 2013.

10. Consumer Healthcare Product Association. Statement from CHPA on Health Canada's Label Updates to OTC Children's Oral Cough and Cold Medicines. Available at: www.chpa-info. org/10_07_08_pedcc.aspx. Accessed Aug 1, 2018.

11. American Academy of Pediatrics. Withdrawal of cold medicines: addressing parent concerns. Available at: http:// www.aap.org/enus/professional-resources/practice-support/ Pages/Withdrawal-of-Cold-Medicins-Addressing-Parent-Concerns.aspx. Accessed: Nov 13, 2013.

12. Goverment of Canada. Health Canada's Decision on Cough and Cold Medicines. Available at: http://www.healthycanadians.gc.ca/recall-alert-rappel-avis/hc-sc/2008/13267a-eng. php\#a1. Accessed Aug 1, 2018.

13. Klein-Schwartz W, Sorkin JD, Doyon S. Impact of the voluntary withdrawal of over-the-counter cough and cold medications on pediatric ingestions reported to poison centers. Pharmacoepidemiol Drug Saf 2010;19:819-24. [CrossRef]

14. Forrester MB. Effect of cough and cold medication withdrawal and warning on ingestions by young children reported to Texas poison centers. Pediatr Emerg Care 2012;28:510-3. [CrossRef]

15. Mazer-Amirshahi M, Reid N, van den Anker J, Litovitz T. Effect of cough and cold medication restriction and label changes on pediatric ingestions reported to United States poison centers. J Pediatr 2013;163:1372-6. [CrossRef]

16. Shehab N, Schaefer MK, Kegler SR, Budnitz DS. Adverse events from cough and cold medications after a market withdrawal of products labeled for infants. Pediatrics 2010;126:1100-7. [CrossRef]

17. Hampton LM, Nguyen DB, Edwards JR, Budnitz DS. Cough and cold medication adverse events after market withdrawal and labeling revision. Pediatrics 2013;132:1047-54. [CrossRef]

18. Mazer-Amirshahi M, Rasooly I, Brooks G, Pines J, May L, Anker Jvd. The Impact of Pediatric Labeling Changes on Prescribing Patterns of Cough and Cold Medications. J Pediatrics 2014;165:1024-8.e1. [CrossRef]

19. Sen EF, Verhamme KM, Felisi M, 't Jong GW, Giaquinto C, Picelli G, et al; TEDDY European Network of Excellence. Effects of safety warnings on prescription rates of cough and cold medicines in children below 2 years of age. Br J Clin Pharmacol 2011;71:943-50. [CrossRef] 